\title{
O SENTIDO DE VOTO DOS ELEITORES RESIDENTES NO ESTRANGEIRO, 1976-2011
}

\author{
Ana Maria Belchior \\ Instituto Universitário de Lisboa (ISCTE-IUL), Centro de Investigação e Estudos de Sociologia \\ (CIES-IUL), Lisboa, Portugal \\ Marco Lisi \\ Faculdade de Ciências Sociais e Humanas (FCSH), Universidade NOVA de Lisboa, Instituto \\ Português de Relações Internacionais (IPRI), Lisboa, Portugal \\ Manuel Abrantes \\ Universidade de Lisboa, Instituto Superior de Economia e Gestão (ISEG), Investigação em \\ Ciências Sociais e Gestão (SOCIUS/CSG), Lisboa, Portugal

\section{Joana Azevedo} \\ Instituto Universitário de Lisboa (ISCTE-IUL), Centro de Investigação e Estudos de Sociologia \\ (CIES-IUL), Lisboa, Portugal
}

\begin{abstract}
Resumo Este artigo tem como objetivo principal analisar o sentido de voto dos portugueses residentes no estrangeiro durante o período democrático (1976-2011), em eleições legislativas, europeias e presidenciais, assim como o papel do sistema de partidos no estrangeiro na mobilização eleitoral e na explicação do sentido de voto. As duas tendências mais importantes que emergem dizem respeito: em primeiro lugar, ao acentuado decréscimo da participação eleitoral deste eleitorado nos dois círculos da emigração, em todos os tipos de eleições; e, em segundo lugar, a uma sistemática maior concentração de votos nos dois principais partidos, em especial no PSD no que respeita ao círculo de fora da Europa.
\end{abstract}

Palavras-chave: emigração portuguesa, eleições, comportamento eleitoral, voto externo.

Abstract The main purpose of this article is to analyse the voting behaviour of Portuguese citizens living abroad during the democratic period (1976-2011), in legislative, European and presidential elections, as well as the role of the system of parties abroad in electoral mobilisation and in explaining the voting behaviour. The two most important trends that emerge are: first, the sharp decrease in the participation of this electorate in both emigration constituencies, in all types of elections; and, second, a greater systematic concentration of votes in the two main parties, especially in the PSD with regard to the circle outside Europe.

Keywords: portuguese emigration, elections, voting behavior, external vote.

Résumé Le but principal de cet article est d'analyser le comportement électoral des citoyens portugais vivant à l'étranger pendant la période démocratique (1976-2011), lors des élections législatives, européennes et présidentielles, ainsi que le rôle du système des partis à l'étranger dans la mobilisation électorale et pour expliquer le comportement électoral. Les deux tendances les plus importantes qui se dessinent sont, d'une part, la forte diminution de la participation de cet électorat dans les deux circonscriptions d'émigration, dans tous les types d'élections et, d'autre part, une plus grande concentration systématique des votes dans les deux principaux partis, notamment au PSD en ce qui concerne le cercle hors Europe.

Mots-clés: émigration portugaise, élections, comportement électoral, vote externe.

Resumen El objetivo principal de este artículo es analizar el comportamiento electoral de los ciudadanos portugueses residentes en el extranjero durante el período democrático (1976-2011), en las elecciones legislativas, europeas y presidenciales, así como el papel del sistema de partidos en el extranjero en la movilización electoral y en la explicación del comportamiento electoral. Las dos tendencias más importantes que emergen son: en primer lugar, la fuerte disminución de la participación de este electorado en las dos circunscripciones de emigración, en todos los tipos de elecciones; y, en segundo lugar, una mayor 


\section{Introdução}

A participação dos emigrantes na vida política dos respetivos países de origem pode ser entendida como um indicador do cumprimento do critério da igualdade política nos regimes democráticos, permitindo que todos os cidadãos contribuam de igual forma para a eleição dos seus representantes (em consonância com a teoria de Dahl, 1998: 37-8, 48-50, 76). No caso português, a concessão de voto aos emigrantes em eleições nacionais, o designado voto externo (ver, por exemplo, Bauböck, 2007: 2398-2399), data de 1976, o que faz de Portugal um dos países com maior longevidade do voto emigrante. Portugal está também entre os poucos países que conferem aos emigrantes a possibilidade de eleger membros do parlamento, a par de França, Croácia e Itália (Fierro, Morales e Gratschew, 2007: 28-29). Não obstante a abertura ao voto deste eleitorado desde o início do período democrático, contemplando a eleição de membros do parlamento em eleições legislativas, assim como a significativa dimensão da emigração portuguesa, a participação eleitoral dos emigrantes portugueses foi diminuindo ao longo deste período. $\mathrm{O}$ fenómeno da muito baixa mobilização política dos emigrantes não é exclusivamente português, mas antes comum à generalidade das comunidades emigrantes (Fidrmuc e Doyle, 2004; Lafleur e Chelius, 2011). Em alguns países, o voto dos emigrantes tem sido, todavia, pontualmente decisivo para os resultados eleitorais nacionais (como se verá adiante). O comportamento eleitoral dos emigrantes merece, por isso, ser melhor compreendido, dada a sua potencial relevância.

A literatura produzida sobre o voto externo tem tido cariz essencialmente teórico ou normativo (Archer, 1991; Levitt e Dehesa 2003; Barry, 2006; Bauböck, 2007; Lafleur e Martiniello, 2009; Caramani e Strijbis, 2012), apesar do volume crescente de trabalhos empíricos nos últimos anos (Fierro, 2002; Chelius, 2003; Fidrmuc e Doyle, 2004; IDEA, 2007; Collyer e Vathi, 2007; Lafleur e Chelius, 2011; Leal, Lee e McCann, 2012; Lafleur, 2013; Lisi et al., 2015; Abrantes et al., 2015). A investigação sobre o tópico é em especial limitada se se considerar estritamente o impacto da participação dos emigrantes na política interna dos países de origem (Smith, 2008; Itzigsohn e Villacrés, 2008), ou o seu sentido de voto em eleições nacionais (Lafleur e Sánchez-Domínguez, 2014; Gamlen, 2015). Tal ficar-se-á a dever em parte à exigência da recolha dos dados, a par de uma baixa recompensa dos resultados devido aos muito baixos números da participação eleitoral.

As crescentes exigências colocadas ao desempenho das instituições democráticas (Norris, 2011), assim como o aumento dos fluxos migratórios dos últimos anos, decorrente da crise económica e financeira que se abateu sobre vários países 
europeus, vieram intensificar a importância política da população emigrada. Existem, contudo, poucos estudos sobre a participação dos emigrantes portugueses na política ou em eleições nacionais. Nestes estudos é possível identificar três linhas principais de reflexão: uma centrada na análise da extensão e alcance dos direitos de participação eleitoral dos portugueses não residentes (Malheiros e Boavida, 2003; Lobo, 2007; Rodrigues et al., 2013; Lisi et al., 2015); outra centrada na análise da participação eleitoral, assente sobretudo na sistematização dos indicadores mais relevantes do voto externo português (Lobo, 2007; Rodrigues et al., 2013; Abrantes et al., 2015); por último, a análise do modo como os partidos se posicionam face aos emigrantes enquanto eleitorado e enquanto tema político (Abrantes et al., 2012; Rodrigues et al., 2013). O presente artigo visa contribuir para melhor compreender esta realidade mediante o estudo longitudinal e detalhado do sentido de voto dos emigrantes portugueses desde a sua implementação em 1976. Comparam-se eleições no território nacional e no estrangeiro, evidenciando as particularidades das eleições no estrangeiro, que apresentam dinâmicas próprias e específicas, que em muitos casos permanecem imunes às mudanças (ou ciclos) eleitorais que emergem a nível nacional.

A importância dos partidos enquanto atores políticos tem sido realçada na pesquisa sobre o voto externo, alertando-se todavia para a escassez de análise das dinâmicas existentes entre os partidos no estrangeiro e o eleitorado emigrante (Barry, 2006; Lafleur, 2013). Este trabalho visa também contemplar este aspeto, procurando-se perceber em que medida as dinâmicas do sistema partidário no estrangeiro (o número de partidos e a sua competitividade eleitoral) contribuem para explicar a mobilização eleitoral e os padrões de voto dos emigrantes portugueses em eleições nacionais.

Esta análise tem propósitos essencialmente exploratórios, visando descrever o quadro longitudinal (1976-2011) do voto externo português em eleições legislativas, europeias e presidenciais. Propõe-se analisar comparativamente os resultados eleitorais nos dois círculos da emigração ao longo do tempo, por tipo de eleição, e por comparação com a realidade nacional, contemplando também o contributo das dinâmicas do sistema de partidos políticos no estrangeiro para a mobilização eleitoral.

Para responder a estas questões utilizam-se dados recolhidos no âmbito do projeto "Votar no Estrangeiro: Participação Política e Cidadania dos Emigrantes Portugueses", ${ }^{1}$ designadamente os dados eleitorais a nível agregado cuja principal fonte é a DGAI (Direcção-Geral da Administração Interna). As conclusões da pesquisa devem ser interpretadas tendo em conta que a inscrição nos círculos da emigração é voluntária e, portanto, que a análise se suporta no número de eleitores recenseados, um número que significativamente subestima o número de potenciais eleitores residindo no estrangeiro.

1 Este projeto foi desenvolvido no CIES-IUL, do Instituto Universitário de Lisboa (ISCTE-IUL), entre 2009 e 2011, com financiamento do Observatório da Emigração. Os dados resultam de um protocolo estabelecido entre o CIES-IUL, a DGAI (Ministério da Administração Interna), e a Comissão Nacional de Eleições (CNE). 


\section{A importância do voto externo e o caso português}

Numa perspetiva teórica, diversos autores da ciência política, da sociologia e do direito têm contribuído para a problematização da figura política constituída pelos emigrantes (Itzigsohn, 2000; Bauböck, 2003; Rubio-Marín, 2006; Barry, 2006; Lafleur, 2013). Tendo-se expandido a nível internacional sobretudo a partir da década de 1980, o direito de voto dos cidadãos residentes no estrangeiro era, à data de um estudo global sobre a matéria (IDEA, 2007), permitido já em 115 países do mundo, 41 dos quais situados na Europa, não obstante as numerosas restrições e dificuldades práticas identificadas em muitos destes países. Como assinala Bauböck (2003: 703, tradução nossa), “o que é novo não é tanto a orientação política dos migrantes de primeira geração em relação aos seus países de origem mas as oportunidades crescentes de que dispõem para combinar estatutos e afiliações externas e internas".

O caminho que se tem esboçado é o de uma democracia em que as lógicas de jus sanguinis e jus solis não se opõem ou negociam, mas antes se conjugam ou acumulam, como mostram autores que procuram enquadrar este fenómeno no debate sobre transnacionalismo político (Itzigsohn, 2000; Bauböck, 2003; Martiniello e Lafleur, 2008). Em comparação com as condições verificadas no passado, as maiores facilidades de circulação que hoje existem na União Europeia, a agilização e a redução de custos dos transportes ou as novas tecnologias da informação e comunicação são alguns elementos a considerar. Por outro lado, a participação eleitoral dos residentes no estrangeiro confronta-se, desde o princípio, com obstáculos associados à relação particular desta população com fatores tipicamente entendidos como pilares do funcionamento democrático, tais como a intermediação desempenhada por parte dos atores institucionais e dos grupos de interesse (Wright, 1995; Van Deth, 1997).

É oportuno recordar que, de acordo com o estudo do IDEA (2007), os primeiros países a implementar o voto externo constituem um grupo heterogéneo, em que a democraticidade do regime, o volume da população emigrante ou a zona geográfica do globo não parecem ter sido relevantes. A implementação do voto externo tem dependido sobretudo de dinâmicas domésticas de legitimação e reconhecimento dos direitos políticos dos emigrantes, colocando-se a hipótese de estarmos a observar menos um desenvolvimento transnacional propriamente dito do que uma soma de desenvolvimentos nacionais. Outra perspetiva defenderá a complementaridade entre o reforço da pertença nacional dos emigrantes e o desenvolvimento de comunidades políticas pós-nacionais ou transnacionais (Rubio-Marín, 2006).

Na generalidade dos países em que o voto dos emigrantes é permitido, o peso eleitoral que lhes está associado é em regra muito limitado (Fierro, Morales e Gratschew, 2007: 28-34). Tal deve-se essencialmente aos constrangimentos do sistema eleitoral, que distorcem a correspondência entre o número de votos e o número de lugares. O impacto do voto dos emigrantes só ocasionalmente tem contribuído para a definição dos resultados eleitorais. As eleições legislativas italianas de 2006 (as primeiras em que o voto externo foi permitido naquele país), e as eleições 
presidenciais cabo-verdianas de 2001 e de 2006 são exemplos paradigmáticos da importância pontual do voto externo, já que o resultado destas eleições foi apenas conhecido depois do apuramento dos votos dos residentes no estrangeiro.

Em Portugal a lei eleitoral estabeleceu desde logo, após a transição para a democracia, a capacidade eleitoral dos emigrantes portugueses em eleições nacionais (inicialmente apenas para as eleições legislativas, mais tarde, em 1987, para as eleições para o Parlamento Europeu; e em 1997 para as eleições presidenciais e referendos). Desde 1976 e até 1987, estabeleceu-se que cada 55.000 votos poderiam eleger um deputado, até ao máximo de dois por cada círculo eleitoral: um para os países europeus e outro para os países de fora da Europa. Com a revisão constitucional de 1989, o número de representantes eleitos pelos dois círculos da emigração passou a corresponder a um total de quatro, dois por cada círculo (para um total de 230 deputados).

Partindo de níveis muito elevados de participação eleitoral em 1976 (na ordem $\operatorname{dos} 80 \%$ ), a participação dos emigrantes portugueses tem vindo a sofrer um decréscimo progressivo e mais acentuado do que o da participação em território nacional. Os resultados das eleições legislativas de 2011 mostram uma percentagem de participação nacional na ordem dos $60 \%$, sendo a participação dos emigrantes para o círculo da Europa apenas um pouco superior a 20\%, e para o círculo de fora da Europa ligeiramente acima dos 10\%. Estes valores são demonstrativos da fraca expressão a que chegou a participação eleitoral dos emigrantes.

Embora a participação eleitoral efetiva seja fraca, o volume de eleitores é elevado: de acordo com os dados da DGAI, em 2011 estavam inscritos para votar 239.809 eleitores pelos círculos da emigração. $\mathrm{O}$ volume total de potenciais eleitores é, no entanto, muito superior. ${ }^{2}$ Com base nos dados recolhidos pelo Observatório da Emigração, estima-se em 2,3 milhões o volume total de portugueses emigrantes, e este valor chega a 5 milhões se se somarem os descendentes de emigrantes portugueses. Com uma presença que se alarga a cerca de 140 países no mundo, a emigração portuguesa com capacidade eleitoral prevalece relevante em muitos dos países de destino tradicionais, tais como, no que respeita à Europa: França, Alemanha e Luxemburgo; e fora da Europa: Brasil, Venezuela, EUA, Canadá e China. Com o recrudescimento da emigração a partir dos anos 2000 tornaram-se ainda relevantes outros países, como o Reino Unido, que é hoje o principal destino da emigração portuguesa, a Espanha e a Suíça, ou ainda, fora da Europa, Angola e Moçambique (Pires et al., 2010, 2016).

Para a presente análise selecionou-se um conjunto de 15 países em que a emigração portuguesa é particularmente significativa. A seleção dos países obedeceu a dois critérios: (a) os países que representam os destinos onde se concentra maior número de emigrantes potenciais eleitores; e, em simultâneo, (b) o conjunto de países que perfazem conjuntamente mais de $90 \%$ dos votos apurados em 2011.

2 Note-se que o recenseamento eleitoral dos emigrantes, ao contrário do que sucede no caso dos residentes em solo nacional, não era no período em análise nem obrigatório nem automático, mas sim optativo. A percentagem de recenseados varia consoante o país de destino e mesmo dentro de cada país. Para o caso dos portugueses nos EUA ver Abrantes et al. (2015). 
Observa-se que, mesmo tendo em conta alguma eventual desatualização dos dados consulares, as taxas de recenseamento são muito baixas, não superando, com exceção do Brasil, os $10 \%$ de inscritos. ${ }^{3}$

\section{O sentido do voto externo: as eleições legislativas}

Um dos traços mais significativos do voto dos emigrantes portugueses em eleições legislativas tem sido a elevada estabilidade do sentido de voto. O padrão do comportamento eleitoral dos emigrantes aponta para uma manifesta preferência pelo PSD no círculo de fora da Europa, enquanto na Europa os mandatos se distribuíram de forma mais equitativa entre os dois principais partidos, PS e PSD. De facto, o PSD tem conseguido praticamente de forma sistemática eleger três deputados, com exceção das eleições de 1985 e de 1999. No primeiro caso o PSD perdeu, no círculo de fora da Europa, um deputado a favor do CDS. Em 1999, foi o PS a beneficiar da perda do deputado pelo PSD não apenas no círculo da Europa, onde conseguiu eleger os dois deputados por esta circunscrição, mas também fora da Europa, sendo a única eleição em que este partido conseguiu eleger um representante neste círculo.

Os partidos políticos mais pequenos têm sido visivelmente marginalizados no que respeita à representação pelos círculos da emigração. Com a exceção do CDS, que conseguiu eleger um candidato em 1985, nenhum outro partido conseguiu eleger representantes. Este facto prende-se essencialmente com a elevada desproporcionalidade do sistema eleitoral, que dificulta a representação dos partidos mais pequenos (Martins e Mendes, 2005; Magalhães, 2005).

A análise detalhada dos votos obtidos em eleições legislativas por cada partido entre 1976 e 2011 permite identificar algumas regularidades e descontinuidades. A nível nacional, a votação média no PSD apresenta um valor ligeiramente superior à do PS, em especial nas primeiras duas décadas do regime democrático. O padrão de voto no estrangeiro apresenta, porém, por comparação com o nacional, uma discrepância muito mais significativa entre estes partidos, com uma média de $46,9 \%$ de votos para o PSD e de apenas $26,4 \%$ para o PS. Esta disparidade é evidenciada no quadro 1 , ao considerarem-se as diferenças entre os votos obtidos a nível nacional e os votos no estrangeiro. O PSD apresenta diferenças negativas, sendo a votação no estrangeiro sistematicamente maior do que a registada a nível nacional (em média superior em quase 11 pontos percentuais). Pelo contrário, o saldo do PS é em geral mais positivo a nível nacional (com cerca de 7 pontos percentuais de votos a mais, em média, a nível nacional). Estas diferenças estruturais entre os dois partidos têm vindo a reduzir-se, sobretudo a partir do fim da década de 1990, o que significa que o padrão de voto nos círculos no estrangeiro tem vindo a ser cada vez mais semelhante ao padrão registado a nível nacional.

3 Os dados relativos aos registos consulares são disponibilizados pela DGACCP e os dados relativos ao número de inscritos no recenseamento eleitoral são disponibilizados pela DGAI-MAI 
Quadro 1 Diferenças dos resultados eleitorais a nível nacional e no estrangeiro (círculos da Europa e fora da Europa) em eleições legislativas por partido político ${ }^{(1)}$

\begin{tabular}{|c|c|c|c|c|c|c|c|c|c|c|}
\hline & \multicolumn{2}{|c|}{ PSD } & \multicolumn{2}{|c|}{ PS } & \multicolumn{2}{|c|}{ PCP } & \multicolumn{2}{|c|}{ CDS-PP } & \multicolumn{2}{|c|}{$\mathrm{BE}$} \\
\hline & $\begin{array}{c}\text { Nacional } \\
\text { menos } \\
\text { estrang. } \\
\text { (pp) }\end{array}$ & $\begin{array}{l}\text { Europa } \\
\text { menos } \\
\text { fora } \\
\text { Europa } \\
\text { (pp) }\end{array}$ & $\begin{array}{c}\text { Nacional } \\
\text { menos } \\
\text { estrang. } \\
\text { (pp) }\end{array}$ & $\begin{array}{l}\text { Europa } \\
\text { menos } \\
\text { fora } \\
\text { Europa } \\
\text { (pp) }\end{array}$ & $\begin{array}{c}\text { Nacional } \\
\text { menos } \\
\text { estrang. } \\
\text { (pp) }\end{array}$ & $\begin{array}{l}\text { Europa } \\
\text { menos } \\
\text { fora } \\
\text { Europa } \\
\text { (pp) }\end{array}$ & $\begin{array}{c}\text { Nacional } \\
\text { menos } \\
\text { estrang. } \\
\text { (pp) }\end{array}$ & $\begin{array}{l}\text { Europa } \\
\text { menos } \\
\text { fora } \\
\text { Europa } \\
\text { (pp) }\end{array}$ & $\begin{array}{l}\text { Nacional } \\
\text { menos } \\
\text { estrang. } \\
(p p)\end{array}$ & $\begin{array}{c}\text { Europa } \\
\text { menos } \\
\text { fora } \\
\text { Europa } \\
\text { (pp) }\end{array}$ \\
\hline 1976 & $-17,1$ & -21 & 6,2 & 39,8 & 8,1 & 8,7 & $-2,6$ & $-26,8$ & - & - \\
\hline 1979 & $-16,2$ & -39 & 8,5 & 27,5 & 10,8 & 10,3 & (1) & (1) & - & - \\
\hline 1980 & $-25,7$ & -37 & 13,9 & 21,6 & 8,9 & 12,8 & (1) & (1) & - & - \\
\hline 1983 & $-13,9$ & $-17,1$ & 17,8 & 26,6 & 9,2 & 14,3 & $-11,8$ & $-23,1$ & - & - \\
\hline 1985 & $-3,9$ & $-16,2$ & 6,3 & 16,6 & 6,4 & 16,3 & $-19,4$ & $-20,5$ & - & - \\
\hline 1987 & $-2,8$ & $-26,4$ & 6,8 & 21,2 & 5,1 & 14,5 & $-10,4$ & $-13,2$ & - & - \\
\hline 1991 & $-15,1$ & $-23,6$ & 11,3 & 26,8 & 4,5 & 6,8 & $-4,6$ & $-11,6$ & - & - \\
\hline 1995 & $-15,7$ & $-36,6$ & 18,4 & 22,0 & 4,5 & 5,2 & 4,8 & 0,5 & - & - \\
\hline 1999 & $-1,6$ & $-23,7$ & $-4,1$ & 17,0 & 5,2 & 3,6 & 5,1 & $-0,1$ & 1,9 & 0,2 \\
\hline 2002 & $-8,0$ & $-28,4$ & 4,1 & 20,7 & 3,6 & 3,9 & 4,4 & 1,6 & 1,9 & 0,6 \\
\hline 2005 & $-9,5$ & $-31,7$ & 1,3 & 26,7 & 4,5 & 3,1 & 3,8 & $-0,2$ & 4,7 & 1,6 \\
\hline 2009 & $-5,1$ & $-30,8$ & 0,6 & 21,0 & 4,7 & 3,4 & 6,2 & 1,6 & 6,0 & 2,7 \\
\hline 2011 & $-2,6$ & $-25,4$ & $-1,9$ & 22,2 & 5,1 & 3,6 & 6,8 & 1,5 & 2,9 & 2,3 \\
\hline Média & $-10,6$ & $-27,5$ & 6,9 & 23,8 & 6,2 & 8,2 & $-1,6$ & $-8,2$ & 3,5 & 1,5 \\
\hline Desvio-padrão & 7,3 & 7,3 & 7,1 & 6,0 & 2,3 & 4,9 & 8,9 & 11,2 & 1,8 & 1,1 \\
\hline
\end{tabular}

${ }^{(1)}$ Todos os quadros e figuras apresentados adotam as designações utilizadas pela Comissão Nacional de Eleições (CNE).

Nota: (1) Coligação AD - Aliança Democrática, composta pelo PPD/PSD, CDS e PPM. Os dados são, por isso, apresentados apenas para o PSD.

Fonte: elaborado com base em dados recolhidos na DGAI/MAI.

Em termos das diferenças entre os dois círculos pela emigração, verifica-se ainda, no quadro 1, que nos países europeus é o PS que apresenta um saldo mais positivo, tendência que se reforça a partir das eleições de 1987, chegando a alcançar mais de $50 \%$ dos votos no círculo. Só a partir de 2009 esta tendência se inflete, mantendo, ainda assim, uma percentagem de votação acima dos $40 \%$. No círculo de fora da Europa, a votação no PS evidencia também tendência para crescer, em especial a partir do final da década de 1990, embora de forma não sustentável e com uma expressão bastante inferior à registada no círculo europeu.

O PSD apresenta, pelo contrário, uma relativa estabilidade da votação no círculo da Europa, com uma média de quase 34\% dos votos. Apenas em 1991 supera os $50 \%$ da votação. No círculo de fora da Europa a expressão de votos no PSD situa-se sistematicamente acima dos $50 \%$, e por vezes substancialmente acima desta percentagem. Como se pode verificar no quadro 1, as diferenças de votação entre estes dois círculos são claramente favoráveis ao PSD fora da Europa, e ao PS na Europa.

Os restantes partidos apresentam votações bastante inferiores aos dois partidos principais. Ao contrário do que acontece a nível nacional, no que respeita ao voto no estrangeiro o CDS obtém, em geral, uma votação mais expressiva 
do que o PCP ${ }^{4}$ afirmando-se estavelmente como o terceiro partido mais votado, com maior sucesso no círculo de fora da Europa. Na Europa, é o PCP a ter uma votação média mais elevada (9,8\% dos votos). Ambos os partidos apresentam, no entanto, um declínio da votação no estrangeiro.

Finalmente, e de forma similar ao que se verifica a nível nacional, o Bloco de Esquerda (BE) registou um volume crescente de votos da emigração desde o seu surgimento em 1999 até 2011. A maior expressão eleitoral do Bloco observa-se no círculo da Europa, onde nas eleições de 2009 conseguiu ultrapassar o PCP, com mais de $4,7 \%$ dos votos. Este círculo é, aliás, de forma geral, favorável aos partidos da esquerda, como se observa pelas diferenças positivas no quadro 1 . A presença do BE tem sido, contudo, a mais marginal no que diz respeito ao voto no estrangeiro.

Ao procurar explicar o sentido das escolhas eleitorais dos imigrantes bolivianos, Lafleur e Sánchez-Domínguez (2014) concluíram que as preferências manifestadas por estes em termos eleitorais refletem em particular as ideias e valores que trouxeram dos seus países de origem, mas também, embora em menor medida, aquelas a que estão expostos nos seus países de destino. A este respeito, importa referir em termos históricos a política de emigração adotada em Portugal pelo Estado Novo. O período de vigência do Estado Novo foi marcado, como evidenciado por Victor Pereira (2014: 37-77), por uma política dúplice face à emigração: uma parte do regime era contrária aos movimentos emigratórios, inscrevendo barreiras à emigração legal; uma outra corrente, e em particular nos últimos anos do regime, preconizava uma abertura à Europa e uma modernização económica que vê a emigração como um recurso importante para o desenvolvimento económico do país (por exemplo, em termos de remessas e regulação do excedente de mão-de-obra).

Após o 25 de Abril, a ação dos partidos conservadores junto dos emigrantes, em particular a influência proeminente do PSD fora da Europa - EUA, América Latina e África (África do Sul, Angola e Moçambique) -, deverá contribuir para explicar em termos históricos o maior apoio dos emigrantes portugueses à ala direita (Lisi et al., 2015: 271-272). Esta identidade ter-se-á consolidado com a capitalização dos temas da emigração pelo PSD, que é, entre os maiores partidos portugueses, aquele que mais eficazmente comunica com as comunidades portuguesas no estrangeiro e o que maior importância programática tem dado aos assuntos que a estas respeitam (Abrantes et al., 2012). Para o posicionamento tradicional do eleitorado emigrante à direita terá também contribuído a sua fraca qualificação média, e proveniência de regiões do país de maior implantação do PSD (Lisi et al., 2015: 271-272), como também já demostrado relativamente aos emigrantes mexicanos (Smith, 2008: 730). Para uma votação mais favorável do PS no círculo da Europa terá claramente contribuído a maior atividade e presença, na fase final do Estado Novo, de ativistas nalguns países

4 Entre 1978 e 1983 o PCP concorreu nas eleições com o Movimento Democrático Português (MDP), formando a coligação da Aliança Povo Unido (APU). Depois das eleições de 1983 formou a coligação eleitoral com o PEV (Partido Ecologista Os Verdes), assumindo a denominação de Coligação Democrática Unitária (CDU) a partir de 1987. A votação do PCP refere-se sempre ao conjunto da coligação em cada momento. 
europeus (Suíça, França e Alemanha), que criaram laços pessoais e redes associativas no território mesmo depois do 25 de Abril (Martins, 2005; Malheiros e Boavida, 2003; Pereira, 2014). Alterações no perfil dos emigrantes durante as últimas décadas, progressivamente mais qualificados, configurando um tipo de emigração mais temporária e com maior densidade de interação com Portugal (Baganha, 2003: 148-150; Pires et al., 2016: 288-290), parecem contribuir para beneficiar gradualmente o voto no PS que, como vimos, se reforça nos dois círculos a partir da segunda metade da década de 1990.

\section{O sentido do voto externo: as eleições europeias e presidenciais}

Por oposição às eleições legislativas, consideradas de primeira ordem, as eleições europeias e presidenciais são eleições de segunda ordem e, por essa razão, geram por comparação com as primeiras uma menor mobilização eleitoral (Marsh e Mikhaylov, 2010). Esta maior abstenção também se observa no caso português, incluindo nos círculos eleitorais dos residentes no estrangeiro (Belchior et al, 2018).

A análise dos quadros 2 e 3 mostra-nos que a percentagem de votos obtida pelos partidos nos círculos dos residentes no estrangeiro não difere muito da nacional. No entanto, no caso do PSD e do PS, este resultado foi quase sempre mais favorável nos círculos do estrangeiro do que a nível nacional, enquanto o inverso se observa para PCP, CDS-PP e BE.

As primeiras eleições para o Parlamento Europeu, realizadas em Portugal em 1987, contaram desde logo com a contribuição do voto dos emigrantes. Estas mantiveram-se todavia restritas à participação de emigrantes residindo em países da União Europeia até 2005, e só nas eleições europeias de 2009 se permitiu a participação dos residentes em países não europeus, assim como em países europeus não pertencentes à UE.

São notórias duas tendências principais no voto dos emigrantes portugueses para as eleições europeias. Em primeiro lugar, verifica-se uma flutuação da votação entre os dois partidos mais votados, o PSD e o PS, com valores médios na casa dos $30 \%$, ligeiramente mais favorável ao PS. Em segundo lugar, o voto no PS varia inversamente ao voto nos dois outros partidos localizados à esquerda - o $\mathrm{PCP}$ e $\mathrm{o}$ $\mathrm{BE}-$, sugerindo uma transferência de eleitorado entre estes. O mesmo não parece verificar-se entre o PSD e o CDS, embora a coligação entre estes dois partidos nas eleições de 2004 impeça uma leitura clara das tendências neste caso.

Reitera-se nestas eleições a tendência para a diferenciação do eleitorado dos dois círculos: fora da Europa significativamente mais apoiante do PSD, e o círculo da Europa mais adepto do PS. O PSD é o partido que aparentemente mais ganha com o alargamento do voto dos emigrantes em eleições para o Parlamento Europeu ao círculo de fora da Europa.

Os resultados eleitorais do PCP no estrangeiro não acompanham a tendência para uma relativa estabilidade da votação neste partido a nível nacional. À exceção das eleições de 2009, eleições em que assegura alguma recuperação, o percurso eleitoral do PCP no estrangeiro tem sido gradualmente decrescente. 
Quadro 2 Diferenças dos resultados eleitorais a nível nacional e no estrangeiro (círculos da Europa e fora da Europa) em eleições europeias por partido político

\begin{tabular}{|c|c|c|c|c|c|c|c|c|c|c|}
\hline & \multicolumn{2}{|c|}{ PSD } & \multicolumn{2}{|c|}{ PS } & \multicolumn{2}{|c|}{ PCP } & \multicolumn{2}{|c|}{ CDS-PP } & \multicolumn{2}{|c|}{ BE } \\
\hline & $\begin{array}{c}\text { Nacional } \\
\text { menos } \\
\text { estrang. } \\
\quad(p p)\end{array}$ & $\begin{array}{c}\text { Europa } \\
\text { menos } \\
\text { fora } \\
\text { Europa } \\
\text { (pp) }\end{array}$ & $\begin{array}{c}\text { Nacional } \\
\text { menos } \\
\text { estrang. } \\
\quad(p p)\end{array}$ & $\begin{array}{c}\text { Europa } \\
\text { menos } \\
\text { fora } \\
\text { Europa } \\
\text { (pp) }\end{array}$ & $\begin{array}{c}\text { Nacional } \\
\text { menos } \\
\text { estrang. } \\
\quad(p p)\end{array}$ & $\begin{array}{c}\text { Europa } \\
\text { menos } \\
\text { fora } \\
\text { Europa } \\
\text { (pp) }\end{array}$ & $\begin{array}{c}\text { Nacional } \\
\text { menos } \\
\text { estrang. } \\
\text { (pp) }\end{array}$ & $\begin{array}{c}\text { Europa } \\
\text { menos } \\
\text { fora } \\
\text { Europa } \\
\text { (pp) }\end{array}$ & $\begin{array}{c}\text { Nacional } \\
\text { menos } \\
\text { estrang. } \\
\text { (pp) }\end{array}$ & $\begin{array}{c}\text { Europa } \\
\text { menos } \\
\text { fora } \\
\text { Europa } \\
\text { (pp) }\end{array}$ \\
\hline 1987 & 1,5 & - & $-5,4$ & - & $-4,4$ & - & 7,9 & - & - & - \\
\hline 1989 & $-1,1$ & - & $-10,2$ & - & 1,8 & - & 6,3 & - & - & - \\
\hline 1994 & $-1,1$ & - & $-7,2$ & - & 3,9 & - & 6,6 & - & - & - \\
\hline 1999 & 7,9 & - & $-0,7$ & - & 5,0 & - & 5,2 & - & 1,5 & - \\
\hline 2004 & $-1,4$ पा & 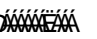 & $-1,5$ & - & 4,9 & - & - & - & 3,0 & - \\
\hline 2009 & $-19,0$ & $-19,7$ & 3,5 & 6,5 & 2,5 & 7,6 & 3,3 & 0,3 & 5,0 & 4,0 \\
\hline Média & $-2,2$ & - & $-3,6$ & - & 2,3 & - & 5,9 & - & 3,2 & - \\
\hline Desvio-padrão & 9,0 & - & 5,0 & - & 3,5 & - & 1,7 & - & 1,8 & - \\
\hline
\end{tabular}

Nota: (1) Em coligação com CDS/PP.

Fonte: elaborado com base em dados recolhidos na DGAI/MAI.

Quadro 3 Resultados eleitorais nas eleições presidenciais (em percentagem)

\begin{tabular}{|c|c|c|c|c|c|c|}
\hline & $\begin{array}{l}\text { Nacional } \\
\text { (A) }\end{array}$ & $\begin{array}{c}\text { Total } \\
\text { estrangeiro } \\
\text { (B) }\end{array}$ & $\begin{array}{c}\text { Europa } \\
\text { (C) }\end{array}$ & $\begin{array}{l}\text { Fora da } \\
\text { Europa } \\
\text { (D) }\end{array}$ & $\begin{array}{l}\text { Diferença } \\
(\mathrm{A}-\mathrm{B}) \\
(\mathrm{pp}) \\
\end{array}$ & $\begin{array}{c}\text { Diferença } \\
\text { (C-D) } \\
(p p)\end{array}$ \\
\hline \multicolumn{7}{|l|}{2001} \\
\hline $\begin{array}{l}\text { Ferreira do Amaral } \\
\text { Fernando Rosas } \\
\text { António Abreu } \\
\text { Jorge Sampaio }\end{array}$ & $\begin{array}{r}34,7 \\
3,0 \\
5,2 \\
55,6 \\
\end{array}$ & $\begin{array}{r}33,1 \\
1,9 \\
4,3 \\
59,2 \\
\end{array}$ & $\begin{array}{r}24,5 \\
2,0 \\
6,4 \\
65,9 \\
\end{array}$ & $\begin{array}{r}42,8 \\
1,8 \\
1,8 \\
51,6 \\
\end{array}$ & $\begin{array}{r}1,6 \\
1,1 \\
0,9 \\
-3,6 \\
\end{array}$ & $\begin{array}{r}-18,3 \\
0,2 \\
4,6 \\
14,3 \\
\end{array}$ \\
\hline \multicolumn{7}{|l|}{2006} \\
\hline $\begin{array}{l}\text { Cavaco Silva } \\
\text { Francisco Louçã } \\
\text { Manuel Alegre } \\
\text { Jerónimo de Sousa } \\
\text { Mário Soares }\end{array}$ & $\begin{array}{r}50,5 \\
5,3 \\
20,7 \\
8,6 \\
14,3 \\
\end{array}$ & $\begin{array}{r}64,6 \\
2,7 \\
12,8 \\
4,6 \\
14,7 \\
\end{array}$ & $\begin{array}{r}49,9 \\
3,9 \\
20,0 \\
7,2 \\
18,5 \\
\end{array}$ & $\begin{array}{r}79,0 \\
1,3 \\
5,4 \\
1,9 \\
10,5 \\
\end{array}$ & $\begin{array}{r}-14,1 \\
2,6 \\
7,9 \\
4,0 \\
-0,4 \\
\end{array}$ & $\begin{array}{r}-29,1 \\
2,6 \\
14,6 \\
5,3 \\
8,0 \\
\end{array}$ \\
\hline \multicolumn{7}{|l|}{2011} \\
\hline $\begin{array}{l}\text { Cavaco Silva } \\
\text { Francisco Lopes } \\
\text { Manuel Alegre } \\
\text { Fernando Nobre } \\
\end{array}$ & $\begin{array}{r}53,0 \\
7,1 \\
19,7 \\
14,1 \\
\end{array}$ & $\begin{array}{r}65,4 \\
5,3 \\
19,6 \\
7,0 \\
\end{array}$ & $\begin{array}{r}45,4 \\
9,1 \\
30,3 \\
10,0 \\
\end{array}$ & $\begin{array}{r}78,3 \\
2,3 \\
10,7 \\
5,0 \\
\end{array}$ & $\begin{array}{r}-12,4 \\
1,8 \\
0,1 \\
7,1 \\
\end{array}$ & $\begin{array}{r}-32,9 \\
6,8 \\
19,6 \\
5,0 \\
\end{array}$ \\
\hline
\end{tabular}

Fonte: elaborado com base em dados recolhidos na DGAI/MAI.

OBE, por seu turno, apresenta nas três eleições europeias em que participou um aumento gradual do seu eleitorado, embora evidencie sempre uma expressão bastante inferior à nacional.

OCDS está entre os partidos com menor expressão eleitoral emigrante em eleições europeias, apresentando o resultado mais fraco de entre os partidos políticos 
portugueses. Tem mantido uma percentagem de votação abaixo dos dois dígitos, e tendencialmente decrescente, à exceção das eleições europeias de 2009. Esta tendência reflete a trajetória eleitoral do CDS a nível nacional em eleições europeias.

No que respeita às eleições presidenciais, cujos dados se apresentam no quadro 3, o comportamento do voto emigrante permite consolidar algumas conclusões prévias. Para as duas vitórias eleitorais de Cavaco Silva nas eleições presidenciais no estrangeiro (com votações na ordem dos 65\%) contribuiu de forma determinante $o$ eleitorado no círculo de fora da Europa (com votações entre 78\% e 79\%). A vitória de Jorge Sampaio no estrangeiro (com uma percentagem de votos ligeiramente inferior a $60 \%$ ) apoiou-se em especial no eleitorado emigrante europeu (65,9\% de votos).

No mesmo sentido, a observação da coluna respeitante à diferença entre a votação na Europa e fora da Europa revela que os candidatos apoiados pelo PSD têm sistematicamente beneficiado de um maior apoio eleitoral no círculo de fora da Europa, enquanto os candidatos apoiados pelo PS, ou ligados a este partido, como é o caso de Manuel Alegre, beneficiam mais do apoio do eleitorado emigrante do círculo europeu. Estes dados reiteram as conclusões obtidas anteriormente.

\section{O sistema partidário nos círculos da emigração}

Com o intuito de explorar em que medida a dinâmica do sistema partidário português no estrangeiro contribui para compreender o padrão do sentido de voto dos emigrantes antes apresentado, analisam-se agora sumariamente duas características do sistema de partidos que expectavelmente ajudam a compreender o comportamento eleitoral dos emigrantes: a fragmentação partidária e a competitividade eleitoral.

Procede-se à análise da evolução da fragmentação partidária nos círculos da emigração por comparação com a nacional usando o número efetivo de partidos eleitorais (NEPE), ${ }^{5}$ que indica o número de partidos efetivamente relevantes no cenário político. Na figura 1 observa-se que o círculo da Europa apresenta uma evolução similar à nacional, enquanto o círculo de fora da Europa destoa significativamente. Em especial, o efeito artificial de redução do número de partidos provocado pelo surgimento da coligação da AD (Aliança Democrática, que uniu o PSD, o CDS/PP e o PPM nas eleições legislativas de 1979 e 1980) é claramente maior no caso dos residentes fora do território europeu. De facto, neste caso a fragmentação apresenta um valor extremamente reduzido, alcançando 1,6 e 1,4 partidos em 1979 e 1980, respetivamente. Este menor número efetivo de partidos no círculo de fora

5 O número efetivo de partidos eleitorais (NEPE), um dos indicadores mais utilizados para medir o nível de fragmentação do sistema de partidos, é medido através do índice de Laakso e Taagepera (1979). Este índice mede a fragmentação do sistema partidário tendo em consideração o peso relativo (a nível eleitoral ou parlamentar) dos partidos. É calculado com base na fórmula: $\mathrm{NEPE}=1 / \Sigma \mathrm{Vi}^{2}$ (sistema partidário eleitoral), onde $\mathrm{V}$ é a proporção de votos obtido pelo partido $i$. Para calcular a fragmentação partidária a nível parlamentar (NEPP) é suficiente considerar a proporção de assentos obtidos por cada partido. 


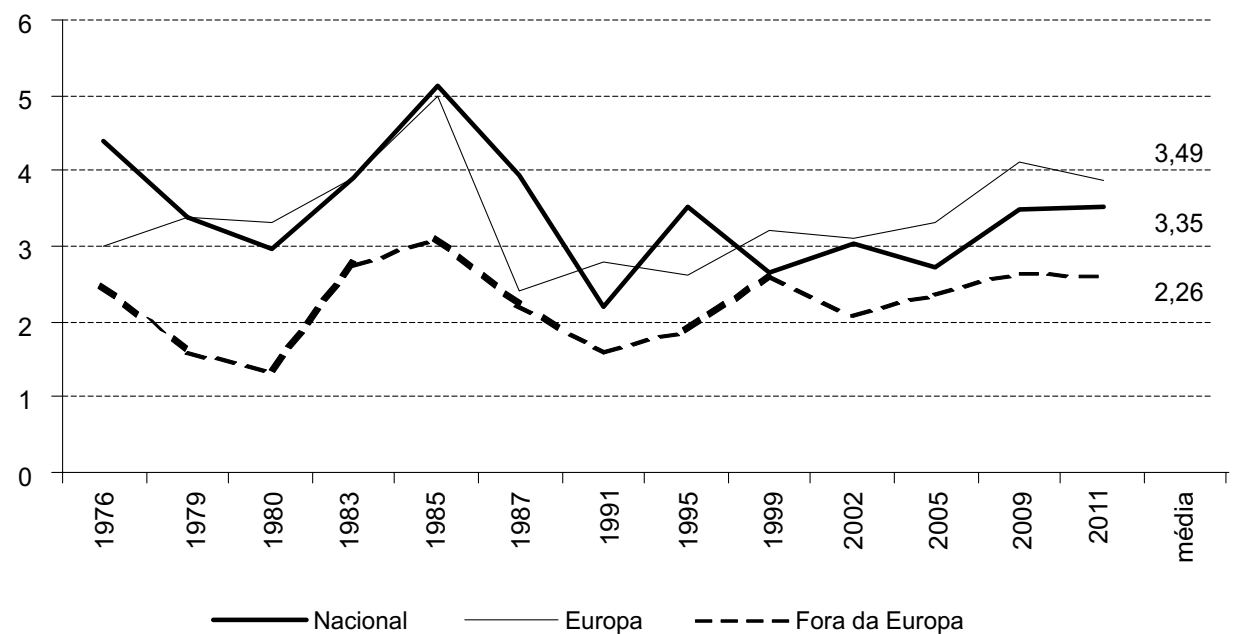

Figura 1 Número efetivo de partidos eleitorais a nível nacional e nos círculos dos residentes no estrangeiro (Europa e fora da Europa)

Nota: os votos brancos e nulos foram considerados juntamente ao voto nos partidos sem representação parlamentar ("outros").

Fonte: elaborado com base em dados recolhidos na DGAI/MAI.

da Europa deve-se em grande medida à hegemonia eleitoral social-democrata e respetiva concentração de votos no PSD nestes países, como antes se verificou.

Não obstante esta tendência, há, todavia, eleições em que as dinâmicas destes dois círculos aparentemente se invertem. O caso mais evidente corresponde às eleições de 1999, em que se regista uma redução significativa do número de partidos no território europeu, enquanto nos restantes países de emigração há uma maior fragmentação. Também nas eleições de 2005 os dois círculos apresentam dinâmicas opostas. Estas duas "exceções" podem relacionar-se com o resultado particularmente positivo obtido pelo PS nos círculos no estrangeiro, contrariando parcialmente a grande predominância do PSD.

A figura 2 sintetiza a evolução da competitividade eleitoral ${ }^{6}$ a nível nacional e nos círculos pelo estrangeiro. Fora da Europa, círculo em que a competitividade eleitoral é menor, o primeiro partido (o PSD) tem sempre conseguido obter um número consistentemente alto de votos (em média cerca de $61 \%$ ), enquanto no círculo europeu a votação tem sido cerca de $42 \%$. O PS tem geralmente obtido a segunda maior percentagem de votos no círculo de fora da Europa, mas houve duas exceções a este padrão: a primeira verifica-se em 1983, depois da queda da aliança do "Bloco Central"; e a segunda regista-se na eleição subsequente, em 1985, em que a emergência do PRD contribuiu para o resultado negativo obtido pelo PS. Como antes observado, na Europa os socialistas têm tido normalmente um maior sucesso, enquanto o PSD conseguiu afirmar-se estavelmente como o segundo partido mais votado. 


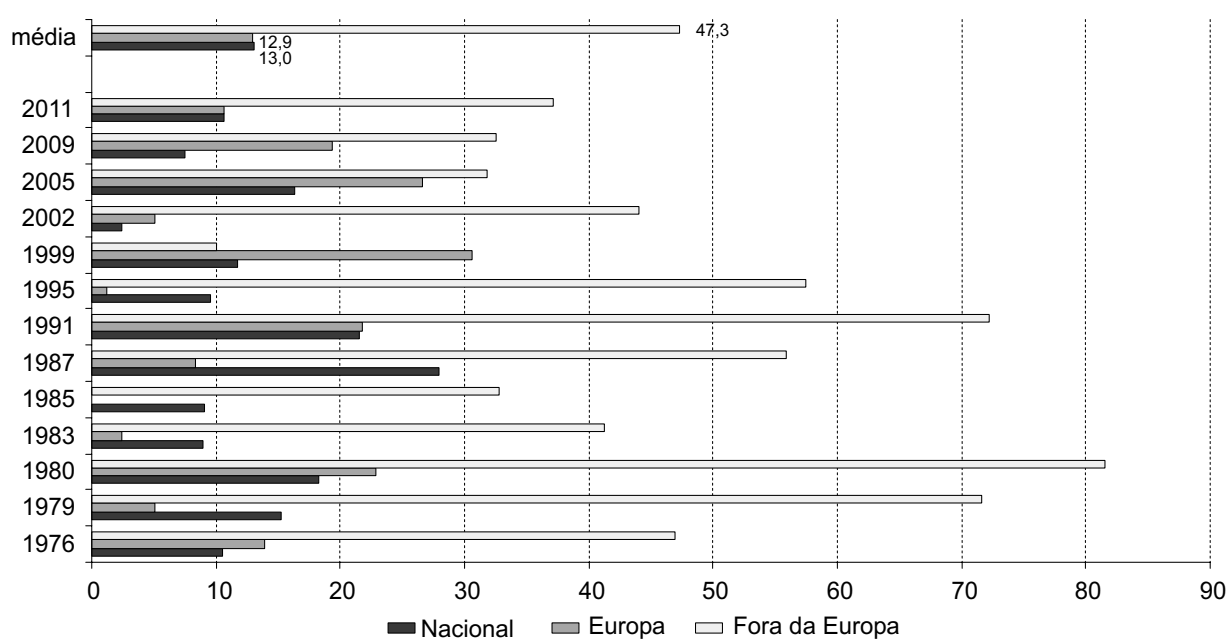

Figura 2 Nível de competitividade a nível nacional e nos círculos pela emigração em eleições legislativas (valores mais elevados $=$ menor competitividade)

Fonte: elaborado com base em dados recolhidos na DGAI/MAI.

emergência do PRD contribuiu para o resultado negativo obtido pelo PS. Como antes observado, na Europa os socialistas têm tido normalmente um maior sucesso, enquanto o PSD conseguiu afirmar-se estavelmente como o segundo partido mais votado.

A principal diferença nos parâmetros da competitividade não é, portanto, entre o território nacional e os círculos do estrangeiro. Enquanto a média nacional e do círculo da Europa é muito semelhante (13\% e 12,9\%), a média da competitividade fora da Europa é de 47,3\%, significando uma muito mais baixa competitividade eleitoral neste último caso. Analisando os resultados com mais detalhe, é possível observar que há neste círculo um maior distanciamento entre os dois partidos mais votados nas eleições de 1979 e 1980, devido sobretudo à formação da coligação da AD. Ao inverso do que sucede a nível nacional, a partir de 1991 a competitividade diminui de forma gradual, alcançando o valor mais baixo nas eleições de 2009, onde a diferença entre os votos obtidos pelo PS e pelo PSD foi apenas de 1,7 pontos percentuais.

Para além de um baixo número efetivo de partidos no sistema, a menor dimensão e a maior desproporcionalidade dos círculos da emigração (ao eleger apenas dois deputados por círculo), quando comparados com os círculos nacionais (Martins, 2004; Martins e Mendes, 2005), contribuem para explicar o padrão de baixa competitividade eleitoral no estrangeiro, assim como o facto de o número de partidos em jogo se cingir, em termos práticos, a dois. Estes são indicadores que parecem estar associados à baixa mobilização eleitoral, assim como ajudam a explicar o padrão de voto da diáspora portuguesa. Por um lado, os eleitores emigrantes tenderão a percecionar a sua participação como pouco relevante, entre outras razões 
porque o sentimento de eficácia política é constrangido pela natureza das regras eleitorais (cf. Norris, 2004); isto é, uma maior mobilização eleitoral não contribuirá para eleger para além de dois deputados por círculo, e dificilmente elegerá um deputado fora do grupo restrito de partidos usualmente elegíveis (PS e PSD), pelo que não existem reais incentivos ao voto fora deste padrão. Por outro lado, ao contribuir para a concentração dos votos nos dois maiores partidos portugueses, do ponto de vista da racionalidade da ação política (Downs, 1957), aqueles indicadores proporcionam baixos incentivos aos partidos mais pequenos para custear uma campanha eleitoral no estrangeiro, em virtude de dividendos limitados; isto é, não havendo um terceiro deputado por círculo, dificilmente estes partidos poderão alcançar representação, pelo que é plausível que tendam a ser parcimoniosos em termos do seu "investimento" no estrangeiro. Estes são, por isso, ingredientes que a somar a outros (como por exemplo a dificuldade dos procedimentos eleitorais) configuram um cenário pouco atrativo para a participação eleitoral, e que conduz à concentração de votos nos dois principais partidos portugueses.

Acresce ainda que os maiores partidos se afiguram eleitoralmente mais beneficiados que os mais pequenos, não apenas porque dispõem de mais recursos e incentivos políticos, mas também porque, em consequência, têm uma maior visibilidade nos meios de comunicação. $\mathrm{O}$ facto de serem partidos de governo permite-lhes projetar a sua imagem mais facilmente para além do território nacional e também utilizar meios e recursos institucionais para, eventualmente, contactar os cidadãos residentes no estrangeiro.

\section{Considerações finais}

Este artigo teve como objetivo principal analisar o sentido de voto dos portugueses residentes no estrangeiro durante o período democrático, assim como o papel do sistema de partidos no estrangeiro na mobilização eleitoral e na explicação do sentido de voto. As duas tendências mais importantes que emergem dizem respeito: em primeiro lugar, ao acentuado decréscimo da participação eleitoral deste eleitorado em todos os tipos de eleições (caracterizada atualmente por uma fraquíssima expressão em eleições de "segunda ordem"); e, em segundo lugar, a uma sistemática maior concentração de votos nos dois principais partidos, em especial no PSD no que respeita ao círculo de fora da Europa.

Apesar de as tendências verificadas nos círculos da emigração (em especial o da Europa) confirmarem o padrão de comportamento dos eleitores a nível nacional no que respeita o aumento da concentração de votos nos dois principais partidos a partir da segunda metade dos anos 80, ou ao declínio da participação eleitoral (embora a um nível bastante menos pronunciado a nível nacional), observam-se dinâmicas diferenciadas nos dois círculos externos, e entre cada um destes e o nível nacional. Em particular, o PSD tem tido tradicionalmente um consenso mais amplo no círculo de fora da Europa, enquanto o PS tem tido um desempenho melhor nos países europeus.

Dada a sistematicidade de resultados mais favoráveis para os social-democratas desde 1976, em especial fora da Europa, a questão que emerge é: por que 
razão o desempenho do PSD é tão positivo junto deste eleitorado? As explicações mais plausíveis residem em fatores de natureza histórico-política (um legado de associação da direita à promoção das causas dos emigrantes, em particular do PSD), fatores relacionados com o perfil social dos emigrantes (caracterizado por baixas qualificações e formação, e provenientes de regiões com forte implementação partidária do PSD), e fatores mais estritamente políticos (relacionados com as estratégias político-partidária em relação a estes eleitorados, e com os incentivos políticos das regras eleitorais). O círculo de fora da Europa compreende ainda um conjunto de países que têm observado menor renovação dos fluxos, face aos países do círculo da Europa (Pires et al., 2016: 65-249). A proximidade geográfica a Portugal, associada a um eventual maior acompanhamento das questões políticas e sociais do país, explica, pelo menos em parte, porque os emigrantes que residem em países europeus denotam um comportamento eleitoral mais similar ao que se verifica a nível nacional. A inexistência de dados desagregados sobre os portugueses a residir no estrangeiro (por exemplo, inquéritos que abarcassem a participação política, representações e práticas dos emigrantes) limita o desenvolvimento de uma análise explicativa mais sólida sobre o seu comportamento eleitoral.

Em geral, as dinâmicas eleitorais entre o círculo da Europa e de fora da Europa são parcialmente diferentes não apenas no que diz respeito ao sentido de voto, mas também em relação à competitividade, com uma maior proximidade do círculo europeu à realidade eleitoral nacional. O reduzido número de partidos políticos relevantes nas disputas eleitorais, assim como a baixa competitividade que as caracteriza, em especial fora da Europa, são indicadores estreitamente associados à desproporcionalidade e pequena magnitude dos círculos eleitorais do estrangeiro, e ajudam a explicar o cenário de baixa mobilização eleitoral e de concentração de votos nos maiores partidos.

Para melhor compreender o papel desempenhado pelos partidos políticos nestes círculos, a sua relação com a fraca mobilização eleitoral, assim como as disparidades da representação partidária nos mesmos, será pertinente um olhar atento sobre os discursos dos líderes políticos e escrutinar os conteúdos dos programas partidários relativamente ao eleitorado emigrante. Esta é uma linha de investigação futura tendo neste sentido já sido concretizado um primeiro empreendimento, que consistiu no estudo aprofundado das estratégias e dinâmicas partidárias nestes círculos para o caso das eleições legislativas de 2009 (Abrantes et al., 2012). Será preciso tomar em consideração que as materializações do transnacionalismo político não se encontram desligadas de perspetivas e disputas ideológicas. O estudo de caso sobre o posicionamento dos partidos políticos nas eleições legislativas de 2009 em Portugal (Abrantes et al., 2012) mostra, nomeadamente, que o peso atribuído à nacionalidade enquanto vínculo e elemento organizador da sociedade é notório nos programas eleitorais que maior atenção prestam à população emigrante (PSD, CDS-PP e PND); já em partidos associados à esquerda parlamentar (PS, PCP), os direitos e a participação dos emigrantes junto das instâncias portuguesas surgem mais frequentemente entrelaçados com os direitos e a participação desses mesmos cidadãos nos países onde residem. Esta constatação pode ajudar a 
compreender o comportamento eleitoral discutido no presente artigo. Há a sublinhar, na senda de autores que têm teorizado diversas formas de transnacionalismo político (Itzigsohn, 2000; Bauböck, 2003; Lafleur, 2013), que os partidos políticos são atores privilegiados na construção de significado em torno da participação eleitoral dos emigrantes. O caráter exploratório do presente estudo e os resultados preliminares que alcançou convidam ao desenvolvimento de mais pesquisa que proceda à confirmação das dinâmicas e padrões encontrados, designadamente mediante estudos comparados, inquéritos aos portugueses residentes no estrangeiro e análises centradas na ação dos partidos.

\section{Referências bibliográficas}

Abrantes, Manuel; Joana Azevedo, Ana Belchior, e Marco Lisi (2012), “Away inside: emigrants and transnationalism through the eyes of political parties", Portuguese Journal of Political Science and International Relations, 8, pp. 61-82.

Abrantes, Manuel; Joana Azevedo, Ana Belchior, e Marco Lisi (2015), “'Nem cá, nem lá?’ Emigrantes portugueses nos EUA e a sua participação em eleições do país de origem", Interdisciplinary Journal of Portuguese Diaspora Studies, 4 (2), pp. 217-239.

Archer, Graça M. (1991), "Processo de votação dos emigrantes dos Estados-membros da Comunidade Económica Europeia", Eleições, 8, pp. 19-29.

Baganha, M. Ioannis (2003), “Portuguese emigration after World War II", em A. Costa Pinto (org.), Contemporary Portugal. Politics, Society and Culture, Boulder, CO, Social Sciences Monographs, pp. 139-157.

Barry, Kim (2006), "Home and away: the construction of citizenship in an emigration context", New York University Law Review, 81, pp. 11-59.

Bauböck, Rainer (2003), “Towards a political theory of migrant transnationalism”, International Migration Review, 37 (3), pp. 700-723.

Bauböck, Rainer (2007), "Stakeholder citizenship and transnational political participation: a normative evaluation of external voting", Fordham Law Review, 75, pp. 2393-2447.

Belchior, Ana Maria, Joana Azevedo, Marco Lisi, e Manuel Abrantes (2018), “Contextual reasons for emigrants' electoral participation in home country elections: the Portuguese case", Journal of Contemporary European Studies, 26 (2), pp. 197-214.

Caramani, Daniele, e Oliver Strijbis (2012), "Discrepant electorates: the inclusiveness of electorates and its impact on the representation of citizens", Parliamentary Affairs, 124, pp. 1-21.

Chelius, Leticia Calderón (coord.) (2003), Votar en la Distancia: La Extensión de los Derechos Políticos a Migrantes, Experiencias Comparadas, México, DF, Instituto Mora.

Collyer, Michael, e Zana Vathi (2007), "Patterns of extra-territorial voting”, Working Paper T22, Sussex Centre for Migration Research.

Dahl, Robert A. (1998), On Democracy, Londres, Yale University Press.

Downs, Anthony (1957), An Economic Theory of Democracy, Nova Iorque, HarperCollins.

Fidrmuc, Jan, e Orla Doyle (2004), "Voice of the diaspora: an analysis of migrant voting behavior", Working Paper n. ${ }^{\circ}$ 712, The William Davidson Institute.

Fierro, Carlos (2002), Estudio Comparado sobre el Voto en el Extranjero, Mexico, DF, IFE. 
Fierro, Carlos, I. Morales, e M. Gratschew (2007), “External voting: a comparative overview", em IDEA (org.), Voting from Abroad. The International IDEA Handbook, Estocolmo e Mexico, DF, IDEA e IFE, pp. 11-34.

Gamlen, Alan (2015), “The impacts of extra-territorial voting: swings, interregnums and feedback effects in New Zealand elections from 1914 to 2011", Political Geography, 44, pp. 1-8.

IDEA - International Institute for Democracy and Electoral Assistance (2007), Voting From Abroad. The International IDEA Handbook, Estocolmo e Mexico, DF, IDEA e IFE.

Itzigsohn, José (2000), "Immigration and the boundaries of citizenship: the institutions of immigrants' political transnationalism", International Migration Review, 34 (4), pp. 1126-1154.

Itzigsohn, José, e Daniela Villacrés (2008), “Migrant political transnationalism and the practice of democracy: Dominican external voting rights and Salvadoran home town associations", Ethnic and Racial Studies, 31 (4), pp. 664-686.

Laakso, Markku, e Rein Taagepera (1979), "Effective" number of parties: a measure with application to West Europe", Comparative Political Studies, 12 (1), pp. 3-27.

Lafleur, Jean-Michael (2013), Transnational Politics and the State. The External Voting Rights of Diasporas, Nova Iorque, Routledge.

Lafleur, Jean-Michael, e Marco Martiniello (2009), Transnational Political Participation of Immigrants, Nova Iorque, Routledge.

Lafleur, Jean-Michael, e Leticia Calderón Chelius (2011), “Assessing emigrant participation in home country elections: the case of Mexico's 2006 presidential elections", International Migration, 49 (3), pp. 99-124.

Lafleur, Jean-Michel, e María Sánchez-Domínguez (2014), “The political choices of emigrants voting in home country elections: a socio-political analysis of the electoral behaviour of Bolivian external voters", Migration Studies (publicado online, disponível em: http://migration.oxfordjournals.org/content/early/2014/04/28/migration.mnu030.abstract).

Leal, David L., Byung-Jae Lee, e James A. McCann (2012), “Transnational absentee voting in the 2006 Mexican presidential election: the roots of participation", Electoral Studies, 31, pp. 540-549.

Levitt, Peggy, e Rafael de la Dehesa (2003), “Transnational migration and the redefinition of the state: variations and explanations", Ethnic and Racial Studies, 26 (4), pp. 587-611.

Lisi, Marco, Ana Belchior, Joana Azevedo, e Manuel Abrantes (2015), “Out of sight, out of mind? External voting and the political representation of Portuguese emigrants", South European Society and Politics, 20 (2), pp. 265-285.

Lobo, Marina Costa (2007), "Portugal: extended voting rights and decreasing participation" em IDEA (org.), Voting from Abroad. The International IDEA Handbook. Estocolmo e Mexico, DF, IDEA e IFE, pp. 83-87

Magalhães, Pedro (2005), “Eleições, partidos e instituições políticas no Portugal democrático", em António Costa Pinto (org.), Portugal Contemporâneo, Lisboa, Publicações Dom Quixote, pp. 173-192.

Malheiros, Jorge, e Maria J. Boavida (2003), “El voto, arma del pueblo: la participación política de los emigrantes portugueses", em Leticia C. Chelius (org.), Votar en la Distancia: La Extensión de los Derechos Politicos a Migrantes, Experiencias Comparadas, México, DF, Instituto Mora, pp. 457-488. 
Marsh, Michael, e Slava Mikhaylov (2010), “European parliament elections and EU governance", Living Reviews in European Governance, 5 (4), pp. 5-30.

Martiniello, Marco, e Jean-Michel Lafleur (2008), “Towards a transatlantic dialogue in the study of immigrant political transnationalism", Ethnic and Racial Studies, 31 (4), pp. 645-663.

Martins, Manuel Meirinho (2004), Participacão Politica e Democracia. O Caso Português (1975-2000), Lisboa, Instituto Superior de Ciências Sociais e Políticas.

Martins, Manuel Meirinho, e Maria de Fátima Abrantes Mendes (2005), 30 Anos de Democracia. Retrospectiva das Eleições para a Assembleia da República (1975-2005), Lisboa, Comissão Nacional de Eleicões.

Martins, Susana (2005), Socialistas na Oposição ao Estado Novo. Um Estudo sobre o Movimento Socialista Português de 1926 a 1974, Lisboa, Casa das Letras.

Norris, Pippa (2004), Electoral Engineering: Voting Rules and Political Behavior, Nova Iorque, Cambridge University Press.

Norris, Pippa (2011), Democratic Deficit: Critical Citizens Revisited, Nova Iorque, Cambridge University Press.

Pereira, Victor (2014), A Ditadura de Salazar e a Emigração. O Estado Português e os Seus Emigrantes em França (1957-1974), Lisboa, Círculo de Leitores/Temas e Debates.

Pires, Rui Pena, et al. (2010), Portugal: Atlas das Migrações Internacionais, Lisboa, Tinta-da-China.

Pires, Rui Pena, Cláudia Pereira, Joana Azevedo, Inês Espírito-Santo, e Inês Vidigal (2016), Emigração Portuguesa. Relatório Estatístico 2016, Lisboa, Observatório da Emigração e Rede Migra, CIES-IUL, ISCTE-IUL. DOI: 10.15847/CIESOEMRE032016

Rodrigues, Frederica, André Freire, Viriato Queiroga, Isabel Estrada Carvalhais, Inês Amador, e Joana Morgado (2013), Participação Eleitoral dos Emigrantes e Imigrantes de Portugal, Lisboa, Organização Internacional para as Migrações, DGAI.

Rubio-Marín, Ruth (2006), “Transnational politics and the democratic nation-state: normative challenges of expatriate voting and nationality retention of emigrants", New York University Law Review, 81, pp. 117-147.

Smith, Robert Courtney (2008), “Contradictions of diasporic institutionalization in Mexican politics: the 2006 migrant vote and other forms of inclusion and control", Ethnic and Racial Studies, 31 (4), pp. 708-741.

Wright, Erik O. (org.) (1995), Associations and Democracy, Londres, Verso.

Van Deth, Jan W. (org.) (1997), Private Groups and Public Life. Social Participation, Voluntary Associations and Political Involvement in Representative Democracies, Londres, Routledge.

Ana Maria Belchior. Professora auxiliar, Instituto Universitário de Lisboa (ISCTE-IUL), Centro de Investigação e Estudos de Sociologia (CIES-IUL), Lisboa, Portugal. E-mail: ana.belchior@iscte-iul.pt

Marco Lisi. Professor auxiliar, Faculdade de Ciências Sociais e Humanas (FCSH), da Universidade NOVA de Lisboa, Instituto Português de Relações Internacionais (IPRI), Lisboa, Portugal. E-mail: marcolisi@fcsh.unl.pt 
Manuel Abrantes. Investigador, Universidade de Lisboa, Instituto Superior de Economia e Gestão (ISEG), investigação em Ciências Sociais e Gestão (SOCIUS/CSG), Lisboa, Portugal. E-mail: mabrantes@socius.iseg.utl.pt

Joana Azevedo. Professora auxiliar, Instituto Universitário de Lisboa (ISCTE-IUL), Centro de Investigação e Estudos de Sociologia (CIES-IUL), Lisboa, Portugal.

E-mail: joana.azevedo@iscte-iul.pt

Receção: 19 de setembro de 2018 Aprovação: 30 de janeiro de 2019 